\title{
Gelişmekte Olan Ülkelerde Kurumlar ve Ekonomik Performans Arasındaki Nedensellik İlişkisi Üzerine Bir İnceleme
}

\author{
An Investigation on The Causality Between Institutions and Economic Performance \\ in Developing Countries
}

\author{
Dr. Öğr. Üyesi İrem ÇETİN
}

\begin{abstract}
$\ddot{O} z$
Kurumsal iktisat yaklaşımı ile birlikte kurumların ülkeler arasındaki ekonomik gelişmişlik farklılıklarını açıklamada en önemli faktörlerden biri olduğu genel kabul görmüş, bu doğrultuda, literatürde, kurumlar ve ekonomik büyüme ilişkisi "kurumların üstünlüğü" varsayımı çerçevesinde incelenmiştir. Söz konusu yaklaşımda, kurumsal yapının iktisadi büyüme ve kalkınmanın altında yatan temel neden olduğu kabul edilmiştir. Ancak tersi yöndeki ilişki, iktisadi büyüme ve kalkınmanın kurumsal performans üzerindeki etkisi üzerinde az durulan konulardan olmuştur. Literatürde, kurumlar ve ekonomik performans arasındaki nedensellik ilişkisini ele alan göreli olarak az sayıdaki çalışmanın sonuçları ise karmaşıktır. Bu çerçevede, çalışmada, gelişmekte olan ülkelerde kurumlar ve ekonomik performans arasındaki nedensellik ilişkisinin panel VECM modeli kullanılarak araştırılması amaçlanmıştır. Çalışmadan elde edilen sonuçlara göre, uzun dönemde, hükümetin etkinliği ve düzenlemelerin kalitesi ile ekonomik büyüme değişkenleri arasında, kurumsal faktörlerden, ekonomik büyümeye doğru bir nedensellik ilişkisi bulunmuştur. Ancak, ekonomik büyümeden hükümetin etkinliği ve düzenlemelerin kalitesine doğru bir nedensellik ilişkisi bulunamamıştır. Diğer taraftan, hukukun üstünlüğü ve ekonomik büyüme arasında çift yönlü bir nedensellik ilişkisi olduğu sonucuna ulaşılmıştır. Çalışmadan elde edilen kısa dönemli nedensellik ilişkilerine ilişkin bulgulara göre ise hükümetin etkinliği ve düzenlemelerin kalitesi ile ekonomik büyüme arasında nedensellik ilişkisi bulunamazken, düzenlemelerin kalitesinden iktisadi büyümeye doğru tek yönlü bir nedensellik ilişsisi olduğu sonucuna ulaşılmıştır.
\end{abstract}

Anahtar Kelimeler: Kurumlar, ekonomik performans, Granger nedensellik

Makale Türü: Araştırma

\begin{abstract}
With the institutional economics approach, it is generally accepted that institutions are one of the most important factors in explaining the differences in economic development among countries, in this framework, the relationship between institutions and economic performance was analyzed based on the assumption of the "primacy of institutions," and in this context, it was admitted that the institutional structure was the main underlying reason for economic growth and development in the literature. However, with regard to the reverse relationship, the effect of economic growth and development on institutional performance has become one of the less emphasized issues in the literature. The results of the relatively few studies in the literature addressing the causality relationship between institutions and economic performance are ambiguous. Within this framework, the study aimed to investigate the causality between institutions and economic performance in developing countries using the panel VECM model. According to the results, while a causality was found from institutional factors to economic growth between the effectiveness of the government and the quality of regulations and economic growth in the long term, it was concluded that there was a bidirectional causality between the rule of law and economic growth. Moreover, it was found that there was a short-term causality from the quality of regulations to economic growth but there is no short-term causality between government efficiency and quality and economic growth.
\end{abstract}

\footnotetext{
${ }^{1}$ Hacettepe Üniversitesi, İktisadi ve İdari Bilimler Fakültesi, Maliye Bölümü, iremyendi@ hacettepe.edu.tr

Atıf için (to cite): Çetin, İ. (2021). Gelişmekte olan ülkelerde kurumlar ve ekonomik performans arasındaki nedensellik ilişkisi üzerine bir inceleme. Afyon Kocatepe Üniversitesi Sosyal Bilimler Dergisi, 23(3), 1014-1022.
} 
Keywords: Institutions, economic performance, Granger causality

Paper Type: Research

\section{Giriş}

Kurumlar, bir toplumda oynanan oyunun kurallarıdır, insanlar arasındaki etkileşimi biçimlendiren insanların getirdiği kısıtlamalardır (North, 2002). Kurumsal iktisat yaklaşımının gelişimi ile birlikte kurumların ekonomik performans üzerindeki etkisi literatürde yer alan teorik ve ampirik çalışmalarda üzerinde önemle tartışılan konulardan olmuştur. Kurumsal iktisat, uzun dönemli ekonomik büyümede kurumların rolüne dikkat çekerek neoklasik iktisat yaklaşımını kurumsal analiz ile birlikte ele almıştır. Literatürde, kurumsal faktörlerin ekonomik performans üzerindeki etkisi sıkça ele alınsa da kurumlar ve ekonomik performans arasındaki nedensellik iliş̧kisi üzerinde az durulan konulardan olmuş, kurumların ekonomik performans etkilediği varsayılmış ancak tersi yöndeki ilişkinin varlığı göz ardı edilmiştir. Bu çerçevede kurumlar ve ekonomik büyüme arasındaki ilişki incelenirken, bir ülkedeki ekonomik gelişmişliğin etkin kurumlara sahip olma üzerindeki etkisinin de araştırılması kurumlar ekonomik büyüme ilişkisinin bir bütün olarak ortaya konulması açısından önem taşımaktadır. Literatürde, yer alan bir kısım çalışmalarda, kurumlar ve ekonomik performans arasında çift yönlü nedensellik ilişkisi olduğu sonucuna ulaş1lırken, diğer kısmında ise nedenselliğin yönünün kurumlardan ekonomik parformansa olduğu sonucuna ulaşılmıştır.

$\mathrm{Bu}$ çalışmada, kurumlar ve ekonomik performans ${ }^{2}$ arasındaki nedensellik ilişkisinin gelişmekte olan ülkeler bağlamında incelenmesiyle literatüre ve güncel politika tartışmalarına katkı sağlanması amaçlanmaktadır. Bu doğrultuda, çalışmanın bir sonraki bölümünde, kurumlar ve ekonomik performans ilişkisine ilişkin literatür taraması yer almaktadır. Çalışmanın ikinci bölümünde ise, ilk olarak çalışmada kullanılan veriler ve yönteme yer verilmekte, daha sonra ise oluşturulan ekonometrik modelden elde edilen sonuçlar ele alınmaktadır. Çalışmanın son kısmında ise, modelden elde edilen sonuçlar gelişmekte olan ülkeler için politika çıkarımları ile birlikte değerlendirilmektedir.

\section{Literatür Taraması}

Ülkeler arasındaki ekonomik performans farkl1l1kları, standart büyüme modellerinde ülkelerin sahip oldukları fiziki, beşeri sermaye stoku ve teknoloji ile açıklanmaya çalışılmıştır. Ancak standart ekonomik teori neden bazı ülkelerin daha az fiziki, beşeri sermaye stokuna ve daha düşük teknoloji seviyesine sahip olduklarını açıklayamamaktadır. Bu nedenle söz konusu faktörler ülkeler arası ekonomik büyüme performansı farklılıklarının temel nedeni değildir. İktisadi büyüme ve kalkınmanın sağlanması için fiziki ve beşeri sermaye stokundaki yetersizlik ve düşük teknolojik gelişmeye neden olan temel faktörlerin araştırılması gerekmektedir. Kurumsal iktisat yaklaşımına göre ülkeler arasındaki söz konusu farklılıkların temel nedeni kurumsal farklılıklardır (Acemoğlu ve Robinson, 2010).

North (2002)'ye göre, kurumlar, bir toplumda oynanan oyunun kurallarıdır, insanlar arasındaki etkileşimi biçimlendiren insanların getirdiği kısıtlamalardır. Kurumlar, insan davranışlarına düzenlilik ve süreklilik kazandırırlar. Formel ya da informel biçimde olabilirler. Kurumların toplumda oynadıkları belki de en önemli rol, ekonomik birimler arasındaki etkileşim için istikrarlı ama ille de etkili olması gerekmeyen bir yapı kurup eğer etkinse, belirsizliği azaltmaktır ki, bu sayede işlem maliyetleri de azalmış olur. Örneğin mülkiyet haklarının korunması belirsizliklerin ve böylece işlem maliyetlerinin azalmasını sağlayarak, bireylerin ya da kuruluşların çalışmalarının karşılığını almasına imkan verecek ve bu sayede bireyler, kuruluşlar, daha çok çalışıp birikim ve yatırım yapacaklar ve sonuçta ekonomik büyüme pozitif yönde etkilenecektir.

\footnotetext{
${ }^{2}$ Çalışmada, ekonomik performans ekonomik büyüme ile ifade edilmektedir.
} 
Kurumsal iktisat yaklașımının gelișimi ile birlikte kurumların ülkeler arasındaki refah farklılıklarını açıklamada temel faktörlerden biri olduğu yaygın olarak kabul edilmiştir. Örneğin, yüksek gelirli ülkelerde, mülkiyet hakları korunmakta, hukukun üstünlüğu temel alınmakta, para ve maliye politikaları sağlam kurumsal çerçevede oluşturulmakta ve söz konusu kurumsal yapı yeni yatırımların gerçekleştirilmesine yönelik motivasyon yaratarak ekonomik büyümeyi pozitif yönde etkilemektedir. Öte yandan, düşük gelirli ülkelere bakıldığında ise, söz konusu kurumsal yapının oluşturulamadığ 1 görülmektedir. Bu noktada, literatürde, bir taraftan kurumsal faktörlerin ekonomik büyümenin nedeni olduğu belirtilirken, diğer taraftan, refah düzeyinin de kurumsal yapının belirleyicisi olabileceği ifade edilmektedir (Rodrik, 2004, s.10).

Literatürde yer alan pek çok ampirik çalışmada, kurumların ekonomik performans üzerinde anlamlı derecede etkili olduğu sonucuna ulaşılmıştır. Örneğin, Mauro (1995), yolsuzluğun ekonomik büyümeyi, negatif yönde etkilediği sonucuna ulaşırken, Knack ve Keefer (1995), bürokrasinin kalitesi, mülkiyet haklarının sağlanması ve politik istikrar ile ekonomik performans arasında pozitif yönlü ilişki olduğu sonucuna ulaşmıştır. Kurumların ekonomik performans üzerindeki etkisi literatürde sıklıkla incelenirken, kurumlar ve ekonomik performans arasında nedensellik ilişkisi üzerinde, daha az durulmuştur. Kurumlar ve uzun dönemli ekonomik büyüme arasındaki ilişkiye ilişskin literatürde iki karşıt görüş bulunmaktadır (Paldam ve Gundlach, 2008). Bunlardan birincisi olan "büyük değişim" (grand transition) yaklaşımına göre, ekonomik büyüme, ekonomide kurumsal değişikliği de içeren her şeyin nedeni kabul edilmektedir. Söz konusu yaklaşımda üretim merkezi öneme sahiptir. Üretim arttı̆̆ında, artan iş bölümü ile toplumlar daha karmaşık hale gelmekte, fiziki ve beşeri sermaye talebinin artması ile birlikte kurumlara yönelik arz ve talep değişmektedir. Üretimin artmasıyla işlem maliyetlerinin azaltılması önem taşımakta kurumsal değişiklik bu yönde gerçekleşmektedir. Söz konusu yaklaşımda, üretim ve kurumlar arasında iki yönlü ilişki olduğu kabul edilmesine rağmen kurumların ekonomik büyümeye etkisinin zayıf olduğu, asıl etkinin ekonomik büyümeden kurumsal değişime doğru olduğu ifade edilmektedir (Paldam ve Gundlach, 2008, s. 68-69). Bu çerçevede, Lipset (1960), ekonomik büyümenin beşeri ve sosyal sermaye birikimini sağlayarak kurumsal yapının gelişmesine katkıda bulunacağını ifade ederken, Glaeser et. al. (2004), toplumdaki gelir seviyesinin artmasıyla birlikte, bürokratik kalite, hukukun üstünlüğü gibi kurumsal kalitenin arttırılmasına yönelik talebin artacağını belirtmiştir. Rigobon ve Rodrik (2005) ise, gelirin kurumsal gelişmeyi pozitif yönde etkilediği sonucuna ulaşmıştır. Kurumlar ve ekonomik performans ilişkisini ele alan ikinci yaklaşım olan "kurumların üstünlüğü" (primacy of institutuions) yaklaşımında ise, kalkınmanın temelinde dışsal olarak belirlenen kurumların olduğu ifade edilmektedir (Paldam ve Gundlach, 2008). "Kurumların üstünlüğü" yaklaşımı Acemoglu et. al. (2005) tarafından kurumların uzun dönem ekonomik büyümenin temeli olduğu belirtilerek ortaya konmuştur. Söz konusu yaklaşımın temelinde, politik kurumlar tarafından belirlenen politik güç bulunmaktadır. Politik güç ise, ekonomik kurumları ve politik kurumları etkilemektedir. Bu çerçevede söz konusu yaklaşımda politik kurumlar temel belirleyici olarak yer almakta, gelirden kurumlara doğru olan etkinin zayıf olduğu belirtilmektedir. Örneğin, hukukun üstünlüğü, mülkiyet haklarının korunması ya da hükümetin etkinliği gibi kurumsal göstergeler ekonomik performansın temel belirleyicisi olarak görülmektedir.

Literatürde, kurumlar ve ekonomik performans arasındaki nedensellik ilişkisini ele alan ampirik çalışmaların sonuçları karmaşıktır. Bazı çalışmalarda, kurumlar ile ekonomik büyüme arasında çift yönlü bir nedensellik ilişkisi olduğu sonucuna ulaşılırken, bazı çalışmalarda da kurumlardan ekonomik büyümeye doğru tek yönlü nedensellik ilişkisi olduğu sonucuna ulaşılmıştır. Chong ve Calderon (2000) 55 ülke için 1972-1995 dönemini kapsayan kurumlar ve ekonomik büyüme arasındaki nedensellik ilişkisini inceledikleri çalı̧̧malarında, kurumlar ve ekonomik büyüme arasında çift yönlü bir nedensellik ilişkisinin olduğu sonucuna ulaşmışlardır. Benzer şekilde, Lee ve Kim (2009), 63 gelişmiş ve gelişmekte olan ülkede 1965-2002 dönemi için gerçekleştirdikleri çalışmalarında kurumlar ve ekonomik büyüme arasında çift yönlü bir nedensellik ilişkisinin olduğu, söz konusu ilişkisinin farklı gelir gruplarında da geçerli olduğunu belirtmişlerdir. Gelişmiş ve gelişmekte olan ülkeler grubu için yapılan bir başka çalışmada ise 
Law ve Bany-Ariffin (2013) grubun bütününde çift yönlü nedensellik ilişkisi geçerliyken, farklı gelir düzeylerinde nedenselliğin değiştiği bu çerçevede, yüksek gelir gruplarında, nedenselliğin yönünün kurumlardan ekonomik büyümeye doğru olduğu sonucuna ulaşırken, düşük gelir kurumlarında da nedenselliğin yönünün tam tersi olduğunu ifade etmişlerdir. Diğer taraftan, Glaeser et. al. (2004), geliş̧miş ve gelişmekte olan ülkeler grubu için yaptıkları çalışmalarında, kurumlar ve ekonomik büyüme arasında nedensellik ilişkisi bulamamışlardır. Literatürde, kurumlar ve ekonomik büyüme arasında tek yönlü nedensellik olduğu sonucuna ulaşan çalışmalarda, Siddiqui ve Ahmed (2009), Pakistan'da kurumlardan ekonomik büyümeye doğru bir nedenselliğin olduğu sonucuna ulaşmışlardır. 13 gelişmekte olan Asya ülkesi için gerçekleştirdikleri çalışmalarında Asghar et. al. (2015) kurumlardan ekonomik büyümeye doğru doğru bir nedensellik ilişkisi olduğunu belirtirken, benzer sonuca Kebede ve Takyi (2017) Sahra Altı Afrika ülkeleri için ulaşmıştır. Ayrıca, Dawson (2003) ve Justesen (2008), gelişmiş ve gelişmekte olan ülkeler grubu için yaptıkları çalışmalarında ekonomik özgürlüğün ekonomik büyümenin nedeni olduğu sonucuna ulaşmışlardır.

\section{Veriler, Yöntem ve Ampirik Sonuçlar}

\subsection{Veriler}

Çalışmada, gelişmekte olan ülkelerde kurumlar ve ekonomik performans arasındaki nedensellik ilişkisini araştırmak amacıyla Dünya Bankası tarafından yapılan sınıflamada orta ve üst gelirli ülkeler grubunda yer alan 47 gelişmekte olan ülkenin ${ }^{3}$ 2002-2017 yılları arasındaki verilerinin yer aldığ 1 bir veri seti kullanılmıştır. Çalışmada, ekonomik performansın bir göstergesi olarak kişi başına düşen reel gelirin logaritmik formu (LNGDP) kullanılırken, kurumsal etkinlik ise üç farklı gösterge ile ele alınarak, üç farklı model çerçevesinde değerlendirilmiştir. Çalışmada, kullanılan kişi başına düşen gelir verisi Dünya Bankası World Development Indicators veri tabanından elde edilirken, kurumsal performansa ilişkin veriler Dünya Bankası World Governance Indicators veri tabanından elde edilmiştir. Çalışmada, kullanılan kurumsal performans göstergelerinden ilki, hükümetin etkinliğidir (GOVEF). Söz konusu endeks, kamu hizmetlerinin kalitesine, kamu hizmetlerinin politik baskılardan uzaklığına, politika oluşturma ve düzenlemenin kalitesi ile hükümetlerin oluşturulan politikalara bağlılığına ilişkin algıyı içermektedir. İkinci gösterge ise, hukukun üstünlüğüdür (RLAW). Hukukun üstünlüğü endeksi, bireylerin toplum kurallarına ne ölçüde itibar ettiğine ve bunlara ne ölçüde uyduğuna, yaptırımların uygulanması, mülkiyet haklarının korunması, polis ve mahkemelerin güvenilirliği ile suç ve şiddet olasılığına ilişkin toplumsal algıyı temsil etmektedir. Kurumsal performansa ilişkin son gösterge olan düzenleyici sistemin kalitesi (REG) ise, özel sektörün gelişimini teşvik eden sağlam politika ve düzenlemeleri hükümetin oluşturma ve uygulama başarısını göstermektedir. Tablo 1'de değişkenlere ilişkin tanımlayıcı istatistikler yer almaktadır.

Tablo 1. Tanımlayıc istatistikler

\begin{tabular}{lcccc}
\hline & LNGDP & GOVEF & LAW & REG \\
\hline Mean & 8.637561 & -0.190000 & -0.331640 & -0.182998 \\
\hline Medyan & 8.642795 & -0.145864 & -0.409856 & -0.103673 \\
\hline Maksimum & 9.929786 & 1.267115 & 1.058083 & 1.240804 \\
\hline Minimum & 7.473713 & -1.947480 & -1.837934 & -2.274461 \\
\hline Standart Sapma & 0.437356 & 0.551797 & 0.596664 & 0.636702 \\
\hline Skewness & 0.098921 & -0.361844 & 0.160179 & -0.684723 \\
\hline Kurtosis & 2.610753 & 3.326137 & 2.539738 & 2.975155 \\
\hline Gözlem Say1S1 & 752 & 752 & 752 & 752 \\
\hline
\end{tabular}

\footnotetext{
3 Söz konusu ülkeler; Arnavutluk, Ermenistan, Arjantin, Azerbaycan, Belarus, Belize, Bosna Hersek, Botsvana, Brezilya, Bulgaristan, Çin, Kolombiya, Kosta Rika, Küba, Dominik, Dominik Cumhuriyeti, Ekvator Ginesi, Ekvator, Fiji Gabon, Gürcistan, Grenada, Guatemala, Guyana, Endonezya, İran, Irak, Jamarika, Ürdün, Kazakistan, Libya, Malezya, Maldivler, Meksika, Namibya, Kuzey Makedonya, Paraguay, Peru, Rusya, Samoa, Sırbistan, Güney Afrika, Saint Lucia, Saint Vincent ve Grenadinler, Tayland, Tonga, Türkiye.
} 


\subsection{Yöntem ve Ampirik Sonuçlar}

Çalışmada, gelişmekte olan ülkelerde kurumlar ve ekonomik performans arasındaki nedensellik ilişkisini araştırmak için panel hata düzeltme modeli (panel VECM) kullanılmıştır. Engle ve Granger (1987) eşbütünleşik değişkenlerin varlığı durumunda standart Granger nedensellik analizinin yanlış sonuçlara yol açacağını ifade etmiş, bu durumda nedensellik analizi için hata düzeltme modelinin kullanılmasını önermişlerdir. Panel VECM, birinci farkı alınmış vektör otoregresif modelin (VAR) bir gecikmeli hata düzeltme terimi (ECT) ile genişletilmesi sonucu oluşturulmuştur. Çalışmada oluşturulan modelin panel VECM gösterimi denklem (1) ve denklem (2)'de yer almaktadır:

$$
\begin{aligned}
& \Delta L N G D P_{i, t}=\delta_{1 i}+\lambda_{1 i} E C T_{i, t-1}+\sum_{p=1}^{k} \delta_{11 i p} \Delta L N G D P_{i t-p}+\sum_{p=1}^{k} \delta_{12 i p} \Delta I N S_{i t-p}+\varepsilon_{1 i, t} \\
& \Delta I N S_{i, t}=\delta_{2 i}+\lambda_{2 i} E C T_{i, t-1}+\sum_{p=1}^{k} \delta_{2 i p} \Delta I N S_{i t-p}+\sum_{p=1}^{k} \delta_{22 i p} \Delta L N G D P_{i t-p}+\varepsilon_{1 i, t}
\end{aligned}
$$

Denklem (1) ve (2)'de $\Delta$ birinci fark işlemcisini, p optimal gecikme uzunluğunu, ECT uzun dönemli eşbütünleşik ilişkiden elde edilen hata düzeltme teriminin gecikmeli değerini, $\varepsilon_{i, t}$ hata terimini ifade etmektedir. Denklemlerde yer alan INS ${ }_{i, t}$ ise kurumsal performansın üç farklı göstergesi olan GOVEF, LAW ve REG değişkenlerini temsil etmektedir. Denklem (1) ve denklem (2) kullanılarak kurumlar ve ekonomik büyüme arasındaki hem kısa hem de uzun dönemli ilişki incelenebilmektedir. Denklem (1)'de kurumlardan ekonomik performansa doğru olan olan kısa dönemli nedensellik ilişkisi Wald testi kullanılarak $\delta_{12 \text { ip }}=0$ boş hipotezinin testi ile araştırılırken, denklem (2)'de ekonomik performanstan kurumlara doğru olan kısa dönemli nedensellik ilişkisi $\delta_{22 i p}=0$ boş hipotezinin Wald testi kullanılarak sınanması ile incelenmektedir. Uzun dönemli nedensellik ilişkisi ise, denklem (1) ve denklem (2)'de sırasıyla $\mathrm{ECT}_{\mathrm{i}, \mathrm{t}-1}$ teriminin katsayıları olan $\lambda_{1 \mathrm{i}}$ ve $\lambda_{2 \mathrm{i}}$ 'nin anlamlılıklarının araştırılması ile bulunmaktadır. Çalışmada, panel VECM modeli sonuçları ele alınmadan önce, modelde yer alan değişkenlerin durağanlığı birim kök testleri kullanılarak araştırılacak daha sonra aynı dereceden durağan olan değişkenler arasında eşbütünleşik bir ilişkinin olup olmadığ 1 incelenecektir.

Tablo 2'de modelde yer alan değişkenlere ilişkin panel birim kök testi sonuçları yer almaktadır. Çalışmada, değişkenlerin durağan olup olmadıklarını araştırmak amacıyla Levin, Lin ve Chu (2002) (LLC), Breitung (2000), Im, Pesaran ve Shin (2003) (IPS), ile Maddala ve Wu (1999) ADF Fisher $\chi^{2}$ (ADF) ve PP Fisher $\chi 2$ (PP) birim kök testleri kullanılmıştır. LLC ve Breitung testleri tüm birimler için ortak bir birim kök sürecinin olduğunu varsayarken, IPS ADF ve PP testleri her bir birimin kendi otokorelasyon sürecine sahip olmasına izin vermektedir. Belirtilen tüm birim kök testlerinde boş hipotez birim kökün varlığını ifade ederken, alternatif hipotez birim kökün olmadığı şeklinde kurulmaktadır. Tablo 2'de yer alan sonuçlara göre, birim kök testlerinin çoğunda değişkenlerin durağan olmadıkları sonucuna ulaşılmıştır. Ancak değişkenlerin birinci farkları alındığında kullanılan tüm birim kök testlerine göre değişkenler $\% 1$ anlamlılık düzeyinde birinci dereceden durağan hale gelmektedir.

\begin{tabular}{|c|c|c|c|c|c|c|c|c|}
\hline & LNGDP & $\triangle \mathrm{LNGDP}$ & GOVEF & $\triangle \mathrm{GOVEF}$ & LAW & $\Delta \mathrm{LAW}$ & REG & $\triangle \mathrm{REG}$ \\
\hline $\begin{array}{l}\text { Levin, Lin } \\
\& \text { Chu }\end{array}$ & $-6.61807 * * *$ & $-8.20604 * * *$ & $-5.38615^{* * *}$ & $-10.1066^{* * *}$ & $-1.71859 * *$ & $-8.91875^{* * *}$ & -1.12982 & $-7.59264 * * *$ \\
\hline $\begin{array}{c}\text { Breitung t- } \\
\text { stat }\end{array}$ & 2.39954 & $-6.21014 * * *$ & 0.33512 & $-7.69347 * * *$ & 2.17863 & $-7.35610^{* * *}$ & -0.25604 & $-5.49883 * * *$ \\
\hline $\begin{array}{c}\text { Im, Pesaran } \\
\text { and Shin W- } \\
\text { stat }\end{array}$ & -0.68557 & $-4.48429 * * *$ & -0.99537 & $-7.71626^{* * *}$ & 0.44403 & $-7.06921 * * *$ & 1.14873 & $-5.97781 * * *$ \\
\hline $\begin{array}{l}\text { ADF Fisher } \\
\text { Chi-square }\end{array}$ & 111.071 & $164.918^{* * *}$ & 110.649 & $228.631 * * *$ & 100.474 & $212.380 * * *$ & 78.0192 & $192.035^{* * *}$ \\
\hline $\begin{array}{l}\text { PP-Fisher } \\
\text { Chi-square }\end{array}$ & 112.743 & $319.820 * * *$ & $165.778 * * *$ & $551.971 * * *$ & 116.492 & $508.534 * * *$ & 127.315 & $567.673^{* * *}$ \\
\hline
\end{tabular}

Tablo 2. Panel birim kök testi sonuçları

Not: $* * *$ ve $* *$ sirasıyla $\% 1$ ve $\% 5$ düzeyindeki istatistiki anlamlılığ 1 göstermektedir. 
Çalışmada, aynı dereceden durağan olan değişkenlerin eşbütünleşik olup olmadığ1 Pedroni (2004) panel eşbütünleşme testi kullanılarak araştırılmıştır. Pedroni (2004) tarafından önerilen teste yedi farklı istatistikle heterojen panellerde eş bütünleşmenin olmadığını ifade eden boş hipotez sınanmaktadır. Söz konusu istatistiklerden dördü kesit içi (within) etkileri kapsayan panel istatistikleri iken, üçü kesitler arası (between) etkileri kapsayan grup istatistikleridir. Pedroni (2004) panel eşbütünleşme testi sonuçları Tablo 3 'te yer almaktadır. Tablo 3'te yer alan sonuçlara göre, Model-1 'de LNGDP ve GOVEF değişkenlerinin panel ve grup istatistiklerinin çoğuna göre \% 1 anlamlılık düzeyinde eşbütünleşik oldukları görülmektedir. Benzer şekilde Model-2'de yedi panel ve grup istatistiğinden beşine göre $\% 1$ anlamlılık LNGDP ve LAW değişkenleri arasında eşbütünleşme ilişkisinin olduğu sonucuna ulaşılmaktadır. Aynı durum Model-3 için de geçerli olmakta yedi istatistikten beşi LNGDP ve REG değişkenleri arasındaki uzun dönemli eşbütünleşik ilişkiyi \%1 anlamlılık düzeyinde doğrulamaktadır.

Tablo 3. Pedroni panel eşbütünleşme testi sonuçları

\begin{tabular}{ll}
\hline Model-1 & \\
\hline Panel v-İstatistiği & -0.619232 \\
\hline Panel rho- İstatistiği & -0.305520 \\
\hline Panel PP- İstatistiği & $-6.355683^{* * *}$ \\
\hline Panel ADF- İstatistiği & $-7.658393^{* * *}$ \\
\hline Grup rho- İstatistiği & 2.361451 \\
\hline Grup PP- İstatistiği & $-9.090346^{* * *}$ \\
\hline Grup ADF- İstatistiği & $-8.531222^{* * *}$ \\
\hline Model-2 & \\
\hline Panel v-İstatistiği & $7.210392^{* * *}$ \\
\hline Panel rho- İstatistiği & -0.414016 \\
\hline Panel PP- İstatistiği & $-7.578916^{* * *}$ \\
\hline Panel ADF- İstatistiği & $-9.564192^{* * *}$ \\
\hline Grup rho- İstatistĭgi & 4.508592 \\
\hline Grup PP- İstatistiği & $-0.951470^{* * *}$ \\
\hline Grup ADF- İstatistiği & $-4.211759^{* * *}$ \\
\hline Model-3 & \\
\hline Panel v-İstatistiği & $4.723263^{* * *}$ \\
\hline Panel rho- İstatistiği & 1.331564 \\
\hline Panel PP- İstatistiği & $-6.132464 * * *$ \\
\hline Panel ADF- İstatistiği & $-9.295384^{* * *}$ \\
\hline Grup rho- İstatistiği & 4.226798 \\
\hline Grup PP- İstatistiğ & $-2.564462^{* * *}$ \\
\hline Grup ADF- İstatistiği & $-3.830775^{* * *}$ \\
\hline Not: *** \%1 düzeyindeki istatistiki anlamlılı̆̆ göstermektedir.
\end{tabular}

Çalışmada, son aşama olarak kurumlar ve ekonomik performans arasındaki uzun ve kısa dönemli nedensellik ilişkisi panel VECM kullanılarak araştırılmıştır. Tablo 4'te yer alan sonuçlara göre Model-1 için uzun dönemde hükümetin etkinliği (GOVEF) ekonomik büyümenin Granger nedeni değildir şeklinde ifade edilen boş hipotez $\% 1$ anlamlılık düzeyinde reddedilmiştir. Ancak kısa dönemde hükümetin etkinliği ekonomik büyümenin Granger nedeni olmadığına ilişkin hipotez reddedilememiştir. Benzer şekilde panel VECM modeli sonuçlarına göre ekonomik büyümenin hükümetin etkinliğin hem kısa hem de uzun dönemde Granger nedeni olmadığı sonucuna ulaşılmıştır. Model-2'nin sonuçlarına göre hukukun üstünlüğü ve ekonomik büyüme arasında uzun dönemde çift yönlü nedensellik ilişkisi bulunurken, aynı değişkenler arasında kısa dönemli bir nedensellik ilişkisi olmadığı sonucuna ulaşılmıştır. Son olarak Model-3'te düzenlemelerin kalitesi hem kısa hem de uzun dönemde ekonomik büyümenin Granger nedenidir. Ancak tersi yönde, ekonomik büyümeden düzenlemelerin kalitesine doğru hem uzun hem de kısa dönemde bir nedensellik ilişki bulunmamaktadır. 
Tablo 4. Panel nedensellik testi sonuçları

\begin{tabular}{|c|c|c|}
\hline & $\begin{array}{l}\text { Uzun Dönem } \\
\text { (ECT) }\end{array}$ & Kısa Dönem \\
\hline \multicolumn{3}{|l|}{ Model-1 } \\
\hline $\begin{array}{l}H_{0} \text { : Hükümetin etkinliği (GOVEF) ekonomik büyümenin granger } \\
\text { nedeni değildir. }\end{array}$ & $-0.035953 * * *$ & 0.044252 \\
\hline $\begin{array}{l}H_{0} \text { : Ekonomik büyüme hükümetin etkinliğinin (GOVEF) granger } \\
\text { nedeni değildir. }\end{array}$ & 0.001300 & 2.237199 \\
\hline \multicolumn{3}{|l|}{ Model-2 } \\
\hline $\begin{array}{l}H_{0} \text { : Hukukun Üstünlüğü (LAW) ekonomik büyümenin granger } \\
\text { nedeni değildir. }\end{array}$ & $-0.033570 * * *$ & 1.775823 \\
\hline $\begin{array}{l}H_{0} \text { : Ekonomik büyüme hukukun üstünlüğü (LAW) granger nedeni } \\
\text { değildir. }\end{array}$ & $-0.003605^{* *}$ & 0.614434 \\
\hline \multicolumn{3}{|l|}{ Model-3 } \\
\hline $\begin{array}{l}H_{0} \text { : Düzenlemelerin kalitesi (REG) ekonomik büyümenin granger } \\
\text { nedeni değildir. }\end{array}$ & $-0.032921 * * *$ & $8.349371 * * *$ \\
\hline $\begin{array}{l}H_{0} \text { : Ekonomik büyüme düzenlemelerin kalitesi (REG) granger } \\
\text { nedeni değildir. }\end{array}$ & 0.000247 & 2.174483 \\
\hline
\end{tabular}

Sonuç ve Öneriler

$\mathrm{Bu}$ çalışmada, kurumlar ve ekonomik performans arasındaki nedensellik ilişkisinin araştırılması amaçlanmıştır. Bu doğrultuda 47 gelişmekte olan ülkenin 2002-2017 yılları arasındaki verileri kullanılmıştır. Çalışmadan elde edilen sonuçlara göre kurumlar ve ekonomik büyüme arasında uzun dönemli bir ilişki bulunmaktadır. Diğer taraftan, panel VECM modeli sonuçları ise, hükümetin etkinliği ve düzenlemelerin kalitesi ile ekonomik büyüme arasında uzun dönemli tek yönlü nedensellik ilişkisi olduğunu gösterirken, hukukun üstünlüğü ve ekonomik büyüme arasında uzun dönemde iki yönlü bir nedensellik ilişkisi bulunmaktadır. Çalışmanın bir diğer sonucuna göre ise, kısa dönemli nedensellik ilişkisi sadece düzenlemelerin kalitesinden ekonomik büyümeye doğrudur.

Çalışmanın gelişmekte olan ülkelerdeki politika oluşturma sürecine ilişkin önemli çıkarımları bulunmaktadır. Buna göre, gelişmekte olan ülkelerde kurumsal kalitenin arttırılması uzun dönemli ekonomik büyümenin sağlanması açısından kritik önem taşımaktadır. Bu nedenle gelişmekte olan ülkelerde politika yapımında miyopik politika uygulamaları yerine kamusal hizmetlerin kalitesinin arttırılması, kamu hizmetlerinin farklı çıkar grupları yerine toplumsal refah dikkate alınarak oluşturulması, toplumsal adalet mekanizmalarının bağımsız bir şekilde işletilmesinin sağlanması, mülkiyet haklarının korunması, uygulanacak kuralların ve yaptırımların şeffaf olması, özel sektörün üretim ve yatırım kararlarını teşvik edecek kurumsal düzenlemelere yönelik reformların uygulamaya konulması gelişmekte olan ülkelerin uzun dönemli ekonomik büyümeyi sağlamasında kritik önem taşımaktadır. Diğer taraftan, çalışmada, elde edilen ekonomik büyümeden hukukun üstünlüğüne doğru var olan nedensellik ilişkisi, gelişmekte olan ülkelerde kurumlar-ekonomik büyüme ilişkisinin bazı noktalarda birbirini besleyen bir süreç olduğunu, kurumsal kalitenin ekonomik büyümeyi pozitif yönde etkilediğini, ekonomik gelişmişliğin de kurumsal performansı pozitif yönde etkilediğini göstermektedir. Çalışmadan elde edilen bir diğer sonuca göre de kurumların ekonomik büyüme üzerindeki etkisi sadece uzun dönemde değil bazı kurumsal göstergeler açısından kısa vadede de görülebilmektedir. Dolayısıyla gelişmekte olan ülkelerde gerçekleştirilecek kurumsal reformlar söz konusu ülkelerde ekonomik büyüme ve kalkınmanın sağlanmasında kritik öneme sahip bulunmaktadir. 


\section{Kaynakça}

Acemoglu, D., Johnson, S. ve Robinson J. A. (2005). Institutions as a fundamental cause of long-run growth. P. Aghion ve S. N. Durlauf (Ed), Handbook of economic growth içinde (ss.386-472). Amsterdam: Elsevier.

Aceomoglu, D. ve Robinson, J. A. (2010). The role of institutions in growth and development. Review of Economics and Institutions, 1(2), 1-33.

Asghar, N., Qureshi, S. ve Nadeem, M. (2015). Institutional quality and economic growth: panel ARDL analysis for selected developing economies of Asia. South Asian Studies, 30(2), 381403.

Breitung, J. (2000). The local power of some unit root tests for panel data. B. Baltagi (Ed), Advances in econometrics: non-stationary panels, panel cointegration, and dynamic panels içinde (ss.161-178). New York: Elsevier.

Chong, A. ve Calderon, C. (2000). Causality and feedback between institutional measures and economic growth. Economics and Politics, 12, 69-81.

Dawson, J.W. (2003). Causality in the freedom-growth relationship. European Journal of Political Economy, 19, 479-495.

Engle, R. ve Granger, C. (1987). Co-integration and error correction: representation, estimation, and testing. Econometrica, 55, 251-76.

Glaeser, E.L., La Porta, R., Lopez-De-Silane, F. ve Shleifer, A. (2004). Do Institutions Cause Growth? Journal of Economic Growth, 9, 271-303.

Im, K.S., Pesaran, M.H. ve Shin, Y. (2003). Testing for unit roots in heterogeneous panels. Journal of Econometrics, 115(1), 53-74.

Justesen, M.K. (2008). The effect of economic freedom on growth revisited: new evidence on causality from a panel of countries 1970-1999. European Journal of Political Economy 24, 642-660.

Kebede, J. G. ve Takyii, P. O. (2017). Causality between institutional quality and economic growth: evidence from Sub-Saharan Africa. European Journal of Economic and Financial Research, 2(1), 114-131.

Knack, S. ve Keefer, P. (1995). Institutions and economic performance: cross-country tests using alternative institutional measures. Economics and Politics, 7, 207-227.

Law, S. H. ve Bany-Ariffin, A.N. (2008). Institutional infrastructure and economic performance: dynamic panel data evidence. Transition Studies Review, 15, 542-557.

Lee, K. ve Kim, B. (2009). Both institutions and policies matter but differently for different income groups of countries: determinants of long-run economic growth revisited. World Development 37, 533-549.

Levin, A., Lin, C.F. ve Chu, C.S.J. (2002). Unit root tests in panel data: asymptotic and finitesample properties. Journal of Econometrics, 108(1), 1-24.

Lipset, S.M. (1960). Political man: the social basis of modern politics. New York: Doubleday.

Maddala, G.S. ve Wu, S. (1999). A comparative study of unit root tests with panel data and a new simple test. Oxford Bulletin of Economics and Statistics, 61(S1), 631-652.

Mauro, P. (1995). Corruption and growth. Quarterly Journal of Economics, 110, 681-712.

North, D. (2002). Kurumlar, kurumsal değişim ve ekonomik performans (Çağal1-Güven G. Çev.). İstanbul: Sabancı Üniversitesi Yayınları. 
Paldam, M. ve Gundlach, E. (2008). Two views on institutions and development: the grand transition vs the primacy of institutions. Kyklos, 61(1), 65-100.

Pedroni, P. (2004). Panel cointegration: asymptotic and finite sample properties of pooled time series tests with an application to the ppp hypothesis. Econometric Theory, 3, 579-625.

Rigobon, R. ve Rodrik, D. (2005). Rule of law, democracy, openness and income: estimating the interrelationships Economics of Transition, 13, 533-564.

Rodrik, D. (2004). Institutions and economic performance - getting institutions right. CESifo DICE Report, 2, 10-15.

Rodrik, D., Subramanian, A. ve Trebbi, F. (2004). Institutions rule: the primacy of institutions over geography and integration in economic development. Journal of Economic Growth, 9, $131-165$.

Siddiqui, D. A. ve Ahmed, Q. M. (2009). The causal relationship between institutions and economic growth: An empirical investigation for Pakistan economy. MPRA Working Pape,r No.19745. https://mpra.ub.uni-muenchen.de/19747/ (Erişim Tarihi: 10.09.2020).

World Bank (2020). World Development Indicators. https://databank.worldbank.org/source/world-development-indicators (Erişim Tarihi: 11.11.2020).

World Bank (2020). World Governance Indicators. https://databank.worldbank.org/source/worldwide-governance-indicators (Erişim Tarihi: 11.11.2020).

\section{ETİK ve BİLIMSEL İLKELER SORUMLULUK BEYANI}

$\mathrm{Bu}$ çalışmanın tüm hazırlanma süreçlerinde etik kurallara ve bilimsel atıf gösterme ilkelerine riayet edildiğini yazar beyan eder. Aksi bir durumun tespiti halinde Afyon Kocatepe Üniversitesi Sosyal Bilimler Dergisi'nin hiçbir sorumluluğu olmayıp, tüm sorumluluk makale yazarlarına aittir. Yazarlar etik kurul izni gerektiren çalışmalarda, izinle ilgili bilgileri (kurul adı, tarih ve sayı no) yöntem bölümünde ve ayrıca burada belirtmişlerdir.

Kurul ad1:-

Tarih:-

No:-

\section{ARAŞTIRMACILARIN MAKALEYE KATKI ORANI BEYANI}

1. yazar katkı oranı : $\% 100$ 